\title{
Strategic Planning How Competitive Factor In Micro And Small Business
}

\author{
Gracelle de Castro Garrido ${ }^{1}$, Patrick Crispim da Silva ${ }^{2}$, Rosimeire Freires Pereira Oliveira ${ }^{3}$, \\ Sidney dos Santos Oliveira ${ }^{4}$.
}

\author{
${ }^{1}$ Faculdade Estácio Amazonas. Av. Djalma Batista, Chapada-Manaus - Amazonas - Brasil. \\ ${ }^{2}$ Faculdade Estácio Amazonas. Av. Djalma Batista, Chapada-Manaus - Amazonas - Brasil. (pcsilva001@ @otmail.com) \\ ${ }^{3}$ Faculdade Estácio Amazonas. Av. Djalma Batista, Chapada-Manaus - Amazonas - Brasil. (rosimeirefpol@ yahoo.com.br) \\ ${ }^{4}$ Secretaria de Educação e Desporto-SEDUC-Manaus- Amazonas-Brasil (sidneyoliveira54@ yahoo.com.br)
}

\begin{abstract}
Micro and Small Enterprises (MSEs) are created in a simpler way than large companies, as well as offer a more personalized service to its customers. They can make your employees identify with the company, see the organization as a whole, understand how the ir work is linked to economic performance and feel responsible for the success or failure of the business. This project aims to assess the importance of strategic planning in the MPE. The research is a qualitative approach to literature, to be held from the survey of theoretical references, already analyzed and published, through electronic and written, such as books, papers, theses, dissertations, websites, web pages and other. In order to gather information or prior knowledge, to analyze the different positions on the research problem. The result of this research allowed us to analyze the strategic planning possibilities are many, from the consultation of specialized companies, courses, hiring independent consultants and entities dedicated to this task, however, is necessary to ensure the professional level of experience to provide the service, know the methodology to be adopted, and business diagnostic capability. A good professional should be able to do these tasks and still be a synergy between contractor and hired.
\end{abstract}

Keywords: Planning. Customers. Consultants.

\section{Planejamento Estratégico Como Fator Competitivo Nas Micro E Pequenas Empresas}

\section{RESUMO}

As Micro e Pequenas Empresas (MPEs), são criadas de forma mais simples do que as empresas de grande porte, além de, prestarem serviço mais personalizado aos seus clientes. Podem fazer com que seus colaboradores se identifiquem com a empresa, visualizem a organização como um todo, entendam como seu trabalho está ligado aos resultados econômicos e se sintam responsáveis pelo sucesso ou pelo fracasso empresarial. Este projeto tem o objetivo de avaliar a importância do planejamento estratégico nas MPE. A pesquisa será na abordagem qualitativa do tipo bibliográfica, a qual será realizada a partir do levantamento de referências teóricas, já analisadas e publicadas, por meio escritos e eletrônicos, como livros, artigos científicos, teses, dissertações, páginas de web sites e outras. Com a finalidade de recolher informações ou conhecimentos prévios, para análise das diversas posições acerca do problema da pesquisa. O resultado desta pesquisa possibilitou analisar que, as possibilidades de planejamento estratégico são muitas, desde a consulta de empresas especializadas, cursos, contratação de consultores independentes e entidades que se dedicam a esta tarefa, entretanto, é necessário certificar o grau de experiência do profissional que prestará o atendimento, conhecer a metodologia a ser adotada, além da capacidade de diagnóstico do negócio. Um bom profissional deve ser capaz de fazer essas tarefas e ainda haver uma sinergia entre contratante e contratado.

Palavras-chave: Planejamento. Clientes. Consultores.

\section{INTRODUÇÃO}

Muitos empreendedores têm ideias de novos negócios e os concretizam na forma de MPE, aproveitando as vantagens que o setor proporciona, como a desburocratização administrativa e jurídica, simplificação nos tributos e o acesso facilitado em determinadas linhas de crédito. Uma empresa bem planejada e estruturada contribui para a geração de empregos diretos e indiretos, ajudam a reduzir as desigualdades sociais e contribuem positivamente para a economia do país. 
O índice de fracasso das MPEs é alto, a instabilidade do mercado e a falta de planejamento são fatores que proporcionam esses acontecimentos. A maioria das pequenas empresas não possui uma cultura de planejamento estratégico e utiliza o conhecimento adquirido ao longo da vida para desenvolver o negócio e isso acaba afetando diretamente a qualidade, eficiência, variedade e outros fatores que são essenciais para o crescimento das vendas e consequentemente o desenvolvimento do empreendimento [1].

Segundo um estudo divulgado pelo [2] de cada cem empresas abertas no Brasil, 48 encerraram suas atividades em três anos. Segundo a pesquisa, de um total de 464.700 empresas que iniciaram suas atividades em $2007,76,1 \%$ continuavam no mercado em 2008, 61,3\% sobreviveram até 2009 e apenas 51,8\% ainda estavam abertas em 2010, ou seja, quase a metade $(48,2 \%)$ fecharam as portas. Diante do exposto, surgiu a seguinte problemática: Quais as principais causas da falência das micro e pequenas empresas em seus primeiros anos de existência?

Algumas hipóteses como o planejamento inadequado, a falta de gestores qualificados e a desmotivação dos funcionários são apontados como a principal causa da falência das micro e pequenas empresas em seus primeiros anos de existência.

As MPEs não fazem um planejamento antes de iniciar seu negócio, nem um objetivo importante para a permanência da empresa. Geralmente, iniciam-se com uma ideia, abrem a empresa e espera o cliente entrar, visando apenas lucro. É investido quase todo o capital próprio e ainda dinheiro de empréstimos numa visão de crescimento. Logo depois, perde-se dinheiro, adquire-se muita dívida e a empresa entra em falência [3].

O objetivo geral da pesquisa é: Avaliar a importância do planejamento estratégico nas micro e pequenas empresas. E os objetivos específicos são: identificar as causas principais da falência das micro e pequenas empresas em seus primeiros anos de existência e analisar as formas de planejamento das MPE.

Este artigo defende a aplicação da metodologia planejamento estratégico como determinante para o sucesso inicial da gestão dos modelos de negócio de pequeno porte.

\section{METODOLOGIA}

A pesquisa será na abordagem qualitativa, quanto aos procedimentos técnicos utilizados para o seu desenvolvimento, ou seja, quanto aos meios, a pesquisa será do tipo bibliográfico, a qual será realizada a partir do levantamento de referências teóricas, já analisadas e publicadas, por meio escritos e eletrônicos, como livros, artigos científicos, teses, dissertações, páginas de web sites e outras, com a finalidade de recolher informações ou conhecimentos prévios, para análise das diversas posições acerca do problema da pesquisa.

\section{O QUE É PLANEJAMENTO?}

Planejar é um processo decisório que procura definir alternativas de curso de ação, apontar as expectativas, objetivos e definir os meios e agentes de execução. Pode ser definido como decisões que se tomam hoje, tendo em vista o futuro [4].

Pressupondo-se que planejamento é a ferramenta para administrar as relações com o futuro, sendo uma aplicação específica do processo de tomar decisões. As decisões que de alguma forma, poderão influenciar o futuro, ou que serão colocadas em prática posteriormente.

Um indivíduo que utiliza o planejamento como uma ferramenta no seu trabalho demonstra um interesse em prever e organizar ações e processos que vão acontecer no futuro, aumentando a sua racionalidade e eficácia de forma a contribuir para o crescimento da empresa. Esse crescimento, resultado de um planejamento bem elaborado implica na perpetuação da empresa em um mercado competitivo, de forma que possam se planejar adquirindo capacidade de enfrentar as adversidades proporcionadas pela globalização [5].

$\mathrm{O}$ conceito de planejamento tem um caráter multidisciplinar, sendo aplicado em vários setores, como por exemplo, o setor econômico, que surgiu depois da II Guerra Mundial em alguns países ocidentais com planos estratégicos e tem como objetivo determinar mecanismo dentro de uma empresa, criando táticas que culminam no benefício. Nesse contexto, existem três níveis de planejamento: estratégico, tático e operacional. $\mathrm{O}$ estudo dos sistemas, originou grandes avanços na área tecnológica do planejamento, revolucionando a educação, a organização militar e a forma como são tratados os problemas ecológicos.

Com o planejamento a empresa ganha efetividade. A efetividade representa a capacidade da empresa coordenar constantemente, no tempo, esforços e energias, tendo em vista, o alcance dos resultados globais e a manutenção da empresa no ambiente. Portanto, para que a empresa seja efetiva, é necessário que ela também seja eficiente e eficaz. É importante salientar que, a eficiência, eficácia e a efetividade são algumas das principais medidas para avaliar uma boa administração, porquanto, normalmente os recursos com os quais o administrador trabalha são escassos e limitados [6].

Em síntese, pode-se observar que, o planejamento consiste em um processo de tomar decisões que envolvem o uso de recursos para realizar atividades com o objetivo de, fornecer um resultado futuro, além de, ser uma importante tarefa de gestão que se relaciona com a preparação, organização e estruturação de um determinado objetivo. É essencial na resolução de problemas e tomadas de decisões

Ao adentrar nas divisões distintas das áreas do planejamento, podendo-se, observar segundo [7] que, o planejamento pode ser dividido em três tipos: 
Gracelle de Castro Garrido, et al. / ITEGAM-JETIA Vol.02, Nº 06, pp.33-38. Junho, 2016.

$\checkmark$ Planejamento estratégico que trata de objetivos da organização como um todo, e são definidos no longo prazo, isto é, entre dois ou mais anos. (Ex.: aumento do retorno sobre o investimento dos acionistas);

$\checkmark$ O planejamento tático que direciona seu foco no planejamento em médio prazo e abrange cada unidade específica da organização, traz, geralmente, objetivos divisionais ou departamentais relacionados com as áreas de produção, finanças, marketing e de recursos humanos da organização. (Ex.: Aumentar a qualidade das peças produzidas);

$\checkmark$ Planejamento operacional que é o mais específico e também o de curto prazo, voltado para a execução das operações cotidianas da organização, referem-se geralmente a cada tarefa ou operação especificamente. (Ex.: contratar dois inspetores da qualidade e incentivar novas ideias para diminuir falhas na produção).

Esses tipos de planejamento concorrem, cada um na sua característica, para que a empresa possa organizar de forma racional todos os pontos necessários ao sucesso de suas operações, sendo que essa divisão busca trazer eficiência ao processo de planejamento de forma a otimizar os métodos.

Em síntese, toda empresa conta com três níveis: administração, decisão e operação, em que o planejamento é um processo desenvolvido com as metas de alcançar os objetivos. Com um planejamento bem feito, otimizando os recursos da organização, as empresas tornam-se mais eficiente e eficazes.

Observa-se que, os principais mecanismos de um bom planejamento é a definição dos objetivos e a execução de planos que integram e coordenam as atividades da organização com a finalidade de atingir a lucratividade desejada.

\section{PLANEJAMENTO ESTRATÉGICO}

A palavra estratégia tem origem grega. Provém de estratego, que significa literalmente a arte da liderança. Era utilizada para designar a função do chefe do exército. Durante vários séculos os militares utilizaram essa palavra para designar o caminho que era dado à guerra, visando à vitória militar. Assim, a elaboração de planos de guerra passou a ser denominada estratégia [8].

Segundo [9] o planejamento estratégico abrange a organização como um todo, não abordando, portanto, detalhes específicos de cada departamento ou divisão. Neste nível, o planejamento é orientado para longo prazo, necessita estabelecer um direcionamento para as estratégias que a organização poderá seguir, e exige a elaboração de planos mais detalhados (táticos ou operacionais).
Planejar estrategicamente significa utilizar os recursos disponíveis de forma eficiente, aumentando a produtividade de um indivíduo ou empresa. A gestão do tempo é crucial para qualquer empresa, por ser um dos recursos mais valiosos à disposição. A gestão estratégica dos riscos também é uma área importante para qualquer empresa.

A parte efetivamente aproveitável do planejamento estratégico, consiste na análise de quatro fatores: Ameaças, oportunidades, pontos fracos e pontos fortes. O grande mérito dessas análises é levar o analista da empresa a considerar os problemas gerais sem se prender aos aspectos particulares, específicos de um setor da empresa. Esse pensamento aberto o leva a considerar quais são os grandes problemas da empresa, dentro da sua capacidade máxima de percepção [10].

Considerado um importante instrumento da administração, o planejamento estratégico, passou a ser utilizado como uma das principais ferramentas de auxílio aos administradores no desempenho de suas tarefas, igualmente como mecanismo útil no alcance dos objetivos desejados. Atualmente, a globalização impulsiona a inovação tecnológica e a concorrência, entre outros fatores, esse processo de modernização tem tornado o planejamento estratégico um mecanismo eficaz.

As pequenas empresas devem atentar para a importância do adequado levantamento de dados relevantes para as ações a serem implementadas, uma amostra inadequada conduzirá a conclusões inverídicas. O planejamento estratégico, deve-se pautar em informações confiáveis, em tempo que se preceda antes da tomada de decisão, na busca de resultados desejados [11].

Em síntese, o planejamento estratégico pode ser simplificado para aplicação nas empresas de pequeno porte, podendo-se utilizar de quatro etapas: Definir e alinhar os objetivos com os resultados desejados; levantar as informações confiáveis, elaborar um planejamento estratégico; executar e monitorar o antes planejado.

\section{MICRO E PEQUENAS EMPRESAS}

A lei geral é o novo Estatuto Nacional das Microempresas (ME) e das Empresas de Pequeno Porte (EPP), instituída pela Lei Complementar n. 123, de 14 de dezembro de 2006, veio estabelecer normas gerais relativas ao tratamento diferenciado e favorecido às MPEs no âmbito dos Poderes da União, dos Estados, do Distrito Federal e dos Municípios, nos termos dos artigos 146, III, "d", 170, IX e 179 da Constituição Federal, esta lei sofreu importantes ajustes pelas Leis Complementares 127/2007, 128/2008, 133/2009 e pela LC 139/2011 e ficou conhecida como a "Lei Geral das Micro e Pequena Empresa" [12].

O Brasil concedeu uma série de benefícios fiscais e simplificações administrativas para as micro e pequenas 
Gracelle de Castro Garrido, et al. / ITEGAM-JETIA Vol.02, Nº 06, pp.33-38. Junho, 2016.

empresas. Houve redução da carga tributária, simplificação da escrituração fiscal, pagamento de vários tributos chamados de Simples Nacional, criado através da Lei Complementar $\mathrm{n}^{\circ}$ 123/2006, responsável pela unificação de vários tributos [13].

Uma das grandes vantagens de abrir uma microempresa é que a burocracia é bem menor em relação às de maior porte, já que uma série de procedimentos são bastante simplificados. Primeiramente, existe o Simples Nacional, regime que garante tratamento tributário diferenciado às microempresas e empresas de pequeno porte. Uma série de tributos federais, estaduais e municipais tais como:

$\checkmark \quad$ Imposto de Renda - Pessoa Jurídica (IRPJ);

$\checkmark$ Imposto sobre Produtos Industrializados (IPI);

$\checkmark$ Contribuição Social Sobre o Lucro Líquido (CSLL);

$\checkmark$ Contribuição para o Financiamento da Seguridade Social (COFINS);

$\checkmark$ Programa de Integração Social (PIS);

$\checkmark$ Instituto Nacional do Seguro Social (INSS);

$\checkmark$ Imposto Sobre Circulação de Mercadorias e Serviços (ICMS);

$\checkmark$ e Imposto Sobre Serviços (ISS).

São pagos em uma única arrecadação, facilitando o seu recolhimento. Também para facilitar os processos administrativos das microempresas, as obrigações previdenciárias e trabalhistas são simplificadas.

Entre as vantagens da microempresa estão à dispensa da necessidade de comunicar férias coletivas ao Ministério do Trabalho e Emprego e a não necessidade de afixação de Quadro de Trabalho (não precisa da anotação do horário de entrada e saída). Além das anteriores, pode-se observar que, possuem vantagens em chamadas publicas podendo participar de uma licitação mesmo não estando em dias com as obrigações fiscais.

Segundo [14] MPE's é resultado de uma política que elimina a burocracia em torno dessas empresas para proporcionar a facilidade e agilidade no funcionamento dos pequenos empreendedores. Mas, por força da lei, essas empresas precisam adotar, para efeito de identificação, sua denominação ou firma, com o uso da expressão microempresa ou então apenas a abreviatura ME.

Segundo o Serviço Brasileiro de Apoio às Micro e Pequenas Empresas (SEBRAE), a microempresa será a sociedade empresária, a sociedade simples, a empresa individual de responsabilidade limitada e o empresário, devidamente registrados nos órgãos competentes, que aufira em cada ano, a receita bruta igual ou inferior a $R \$ 360.000,00$. Se a receita bruta anual for superior a $\mathrm{R} \$ 360.000,00$ e igual ou inferior é $\mathrm{R} \$$ 3.600.000,00, a sociedade será enquadrada como empresa de pequeno porte. Estes valores, referem-se a receitas obtidas no mercado nacional. A empresa de pequeno porte não perderá o seu enquadramento se obter adicionais de receitas de exportação, até o limite de $\mathrm{R} \$ 3.600 .000,00$.

Além desse critério, outro bastante difundido é o que considera o número de funcionários empregados na empresa conforme Tabela 1.

Tabela 1: classificação das empresas por número de funcionários

\begin{tabular}{|c|c|c|}
\hline \multirow[t]{2}{*}{ Porte da empresa } & \multicolumn{2}{|c|}{ Números de Funcionários } \\
\hline & $\begin{array}{l}\text { Comércio e } \\
\text { Serviços }\end{array}$ & Indústria \\
\hline $\begin{array}{l}\text { Micro } \\
\text { empreendedor } \\
\text { Individual }\end{array}$ & Até 2 & Até 2 \\
\hline Microempresa & Até 9 & Até 19 \\
\hline $\begin{array}{ll}\text { Empresa } & \text { de } \\
\text { pequeno porte }\end{array}$ & 10 a 49 & 20 a 99 \\
\hline
\end{tabular}

Fonte: SEBRAE (classificação utilizada pela área de pesquisa do SEBRAE), 2010.

Segundo um estudo divulgado pelo IBGE (Instituto Brasileiro de Geografia e Estatística), com informações de 2010, de cada cem empresas abertas no Brasil, 48 encerraram suas atividades em três anos.

De acordo com a pesquisa, de um total de 464.700 empresas que iniciaram suas atividades em 2007, 76,1\% continuavam no mercado em 2008, 61,3\% sobreviveram até 2009 e apenas $51,8 \%$ ainda estavam abertas em 2010, ou seja, quase a metade $(48,2 \%)$ fecharam as portas.

Visto que, os recursos são altamente limitados, numa estrutura organizacional que tende a ser simples e nem sempre é definida claramente, a maioria das vezes o sistema de controle geralmente são informais, com pouco número de níveis hierárquicos e com centralização das decisões, tendo o acesso aos meios tecnológicos um tanto limitados, nem sempre possuem especializações e o acesso às fontes de capital de giro e às inovações tecnológicas quase sempre é insuficiente, com deficiência no recrutamento e manutenção de mão-de-obra.

Entretanto, apesar das reconhecidas dificuldades que enfrentam as pequenas empresas para viabilizar seus modelos de negócios, são vistas, como uma parcela do PIB importante, e que devem ter um adequado planejamento estratégico para ter como subsídio chaves para o processo decisório, permitindo o crescimento da empresa.

As principais causas do fechamento das empresas nos três anos iniciais são apontadas na Tabela 2: 
Gracelle de Castro Garrido, et al. / ITEGAM-JETIA Vol.02, Nº 06, pp.33-38. Junho, 2016.

Tabela 2 - Principais causas do fechamento das empresas

\begin{tabular}{|l|l|}
\hline $\begin{array}{l}\text { Fatores contribuintes } \\
\text { do fechamento de } \\
\text { empresas }\end{array}$ & Principais Recomendaçães \\
\hline $\begin{array}{l}\text { Ausência } \\
\text { comportamento do } \\
\text { empreendedor }\end{array}$ & $\begin{array}{l}\text { Participação em cursos sobre empreendedorismo } \\
\text { pode ajudar. }\end{array}$ \\
\hline $\begin{array}{l}\text { Ausência } \\
\text { planejamento prévio do }\end{array}$ & $\begin{array}{l}\text { Participação em cursos de planejamento e um } \\
\text { preparo mais apurado antes da abertura (maior tempo } \\
\text { e maior profundidade no planejamento) podem } \\
\text { ajudar. }\end{array}$ \\
\hline $\begin{array}{l}\text { Deficiência na gestão } \\
\text { empresarial }\end{array}$ & $\begin{array}{l}\text { Cursos de gestão empresarial, participação em } \\
\text { palestras e ações conjuntas com empresas do mesmo } \\
\text { ramo podem ajudar }\end{array}$ \\
\hline $\begin{array}{l}\text { Insuficiência } \\
\text { políticas de apoio de }\end{array}$ & $\begin{array}{l}\text { As políticas de apoio têm evoluído positivamente, } \\
\text { mas podem ser aperfeiçoadas (p. ex., reduzindo o } \\
\text { peso dos impostos e da burocracia, ampliando o } \\
\text { crédito para a produção e maior acesso às compras } \\
\text { governamentais). }\end{array}$ \\
\hline $\begin{array}{l}\text { Problemas } \\
\text { conjuntura econômica }\end{array}$ & $\begin{array}{l}\text { É preciso ter continuidade no crescimento da } \\
\text { economia, na estabilidade de preços e na recuperação } \\
\text { da renda dos trabalhadores. }\end{array}$ \\
\hline Problemas pessoais & $\begin{array}{l}\text { Maior profissionalismo, melhor divisão de tarefas, } \\
\text { maior delegação de responsabilidades e separação da } \\
\text { vida pessoal dos negócios podem reduzir esses } \\
\text { impactos. }\end{array}$ \\
\hline
\end{tabular}

Fonte: [15].

No Brasil, atualmente existem aproximadamente nove milhões de Micro e Pequenas Empresas em todo País, que representam mais da metade dos empregos formais, entretanto havia a necessidade de saber o quanto elas contribuem para o Produto Interno brasileiro. Em 1985, o IBGE calculou em 21\% a participação dos pequenos negócios no PIB.

Como não havia uma atualização desse indicador desde então, o SEBRAE contratou a Fundação Getúlio Vargas para avaliar a evolução deste indicador. E o resultado foi muito positivo: em 2001, o percentual cresceu para $23,2 \%$ e, em 2011, atingiu 27\% - ou seja, mais de um quarto do PIB (Produto Interno Bruto) brasileiro é gerado pelas pequenas empresas.

Nesse contexto, conforme mostram dados levantados, as MPEs exercem uma força bastante considerável na formação do PIB, sendo assim, desconsidera-las e não prezar por medidas conjuntas que favoreçam esta parcela do mercado brasileiro é trazer prejuízos para a sociedade, uma vez que estas proporcionam um meio de renda para os empregados e uma fonte de recursos para o governo, que arrecada impostos incidentes sobre a operações destas empresas, fatos estes que tanto beneficiam a as pequenas empresas, como uma sociedade em geral.

\section{CONSIDERAÇÕES FINAIS}

Segundo o presidente do SEBRAE, a taxa de mortalidade empresarial vem diminuindo nos últimos 10 anos, e em julho de 2013 a sobrevivência chegou a 76\%. Há dez anos, esse índice era de 50\%.

A atual taxa mostra uma melhor capacidade das micro e pequenas empresas para superar dificuldades nos primeiros dois anos de vida. Nesse período inicial, a empresa ainda não é conhecida no mercado, não possui carteira de clientes e, muitas vezes, os empreendedores ainda desenvolvendo a capacidade gerencial.

A fase inicial de uma empresa é considerada crucial para a sua permanência; portanto, deve-se haver um investimento na área gerencial, criando um bom planejamento estratégico.

Conclui-se que, os pequenos negócios têm papel de destaque na economia, por corresponder por boa parte da geração de empregos no país, contribuindo com um percentual significativo do PIB brasileiro. Além de, sustentar a economia nos momentos de crise, agregam valor aos produtos e serviços em que as suas atividades estão relacionadas.

Em síntese, as MPEs vêm contribuindo de forma significativa para a geração de empregos e o crescimento da economia brasileira. De acordo com o SEBRAE o Brasil é um dos países mais empreendedores do mundo, com aproximadamente nove milhões de micro e pequenas empresas, fica evidente que este é um setor estratégico para o crescimento de um país.

Contudo, por suas limitações que são características presentes aos moldes dos pequenos modelos de negócio, as MPEs não devem atuar em várias frentes simultaneamente, necessitando analisar e direcionar estrategicamente suas ações para otimizar os recursos tais como: financeiros, tempo, mão de obra, entre outros.

Dessa forma, atendendo aos objetivos os benefícios do planejamento estratégico estão expressos na forma do auxílio direto à operacionalização e de suporte ao modelo de negócio, atuando pró ativamente para o mapeamento de potenciais problemas de cunho estratégico de forma a oferecer a qualificação necessária para tal respondendo a problemática, observa-se que o planejamento estratégico de forma objetiva aplicados nas MPEs deve ainda focar os recursos e principais ações para atingir os objetivos e metas da organização, isto principalmente para as pequenas empresas pode significar o diferencial entre se manter operante e encerar suas atividades.

\section{AGRADECIMENTOS}

Ao Instituto de Tecnologia e Educação Galileo da Amazônia (ITEGAM), ao PPGEP do Instituto de Tecnologia Universidade Federal do Pará (ITEC-UFPA) e a Universidade Estácio de Sá pelo apoio financeiro a pesquisa. 
Gracelle de Castro Garrido, et al. / ITEGAM-JETIA Vol.02, № 06, pp.33-38. Junho, 2016.

\section{REFERÊNCIAS}

[1] FIGUEIREDO, D. A. et al., O impacto do planejamento estratégico na longevidade de micro e pequenas empresas da região bragantina. Bragança Paulista. SP. out. 2014. Disponível em: file:///C:/Users/lucykelly/Downloads/254-855-1-PB\% 20(3). pdf. Acesso em: 11 jun. 2015

[2] IBGE (Instituto Brasileiro de Geografia e Estatística). 2010. Disponível em: <http://ibge.gov.br/home/estatistica/economia/ microempresa/default.shtm>.

[3] MIRANDA, I. T, et al. A importância do planejamento estratégico para o crescimento das empresas. Maringá. SP. v.2. n.1, p. 34-39. jan./jun. 2005.

[4] GURGEL, C.; RODRIGUEZ, M.V. Elementos Essenciais para a Gestão das Organizações. 2. ed. São Paulo. SP: Editora Atlas. 2014. 270p.

[5] MAXIMIANO, A.C. Introdução à administração. 6. ed. São Paulo: Atlas S.A. 2004.

[6] CUNHA, A. S.; SOARES T. C. Aspectos Relevantes do Planejamento das Micro e Pequenas empresas (MPE). Revista da Micro e Pequena Empresa. Campo Limpo Paulista. v.4. n.3. p.15-39. 2010 (set/dez).

[7] CHIAVENATO, I. Introdução à teoria geral da administração. 8. ed. Rio de Janeiro, RJ: ed. Campus. 2011.

[8] TERENCE, A. C. Planejamento estratégico como ferramenta de competitividade na pequena empresa: Desenvolvimento e avaliação de um roteiro tático para o processo de elaboração do planejamento. 2002. $211 \mathrm{f}$. Dissertação (Mestrado em Engenharia de Produção) - Escola de Engenharia de São Carlos, Universidade de São Paulo. São Carlos. 2002.

[9] ANDRADE, A. R Planejamento estratégico. 1. ed. São Paulo. SP: Editora Atlas. 2012. 182 p.

[10] ZACCARELLI, S. B. Estratégia e sucesso nas empresas. 2. ed. São Paulo. SP: ed. Saraiva. 2012. 249p.

[11] SOUZA, N.; QUALHARINI, E. O Planejamento estratégico nas micro e pequenas empresas. III Workshop Gestão Integrada: Riscos e Desafios. Centro universitário Senac. Rio de Janeiro - RJ, 25 e 26 maio. 2007. Disponível em:<http://www.sp.senac.br/pdf/24848.pdf>. Acesso em: 03 nov. 2015.

[12] SEBRAE. Lei Geral das Micro e Pequenas Empresas: Distinções entre microempresa, pequena empresa e MEI. 2010. Disponível em: <http://www.sebrae.com.br/sites/ PortalSebrae/ artigos/ Entenda- as-distinções-entre-microempresa,-pequenaempresa-e-MEI>. Acesso em: 06 de Nov. 2015.
[13] PAES. N. L. Simples Nacional no Brasil: o difícil balanço entre estímulos às pequenas empresas e aos gastos tributários. Economia - PIMES/UFPE, Belo Horizonte. v. 24. n.3. set/dez. 2014. Disponível em:<http://www.scielo.br/ scielo.php? pid=S0103$63512014000300541 \&$ script=sci_arttext $>$. Acesso em: 05 nov. 2015.

[14] DUARTE, E. M. O Empreendedorismo nas micro e pequenas empresas: um estudo aplicado à cidade de Pará de Minas - MG. Faculdade Pedro Leopoldo. Minas Gerais. 2013. Disponível

em:http:<//www.fpl.edu.br/2013/media/pdfs/mestrado/dissertaco es_2013/dissertacao_ednei_magela_duarte_2013.pdf $>$. Acesso em: 21 out. 2015.

[15] 10 anos de monitoramento da sobrevivência e mortalidade de empresas. São Paulo: SEBRAE-SP. 2008.

Participação das Micro e Pequenas Empresas na Economia Brasileira. julho/2014. Disponível em: http:<//www.sebrae.com.br/Sebrae/Portal\%20Sebrae/Estudos\%2 $0 \mathrm{e} \% 20$ Pesquisas/Participacao $\% 20$ das $\% 20$ micro\%20e\%20pequen as\%20empresas.pdf> Acesso em: 06 de nov. 2015. 